Original Article

\title{
Effects of 8 weeks of modified hatha yoga training on resting-state brain activity and the p300 ERP in patients with physical disability-related stress
}

\author{
Amornpan Ajumaporn, PT, $\mathrm{PhD}^{1)^{*}}$, Sunisa Rachiwong, $\mathrm{MSc}^{1,2)}$, \\ Vorasith SiripoRnPANICH, MD ${ }^{3)}$ \\ 1) College of Sports Science and Technology, Mahidol University: Salaya, Nakhonpathom 73170, \\ Thailand \\ 2) Faculty of Science and Technology, Suan Sunandha Rajabhat University, Thailand \\ 3) Research Center for Neuroscience, Institute of Molecular Biosciences, Mahidol University, Thailand
}

\begin{abstract}
Purpose] We examined the effects of Hatha yoga on EEG and ERP in patients with physical disabilityrelated stress. [Participants and Methods] Eighteen male and female injured workers with high stress levels, aged between 18 to 55 years, were evenly divided into two groups: untrained (CG) and trained (TG) modified hatha yoga groups. A modified Hatha yoga protocol was designed for this population by two certified yoga instructors, approved by a physical therapist, and conducted for one hour, three times weekly for 8 weeks. [Results] The results indicated a significant increase in alpha EEG activity over the frontal, central, and parietal electrodes and the delta EEG activity over the centroparietal electrode from pre- to post-training in TG. In addition, significantly faster auditory reaction time for target stimuli, as well as lower P300 peak latency of ERP in auditory oddball paradigm were obtained in TG after 8 weeks of yoga training compare to CG. [Conclusion] Changes in brain activity and ERP components following yoga training would support the psychophysiological effects of hatha yoga as an adjunct to routine rehabilitation.

Key words: Auditory reaction time, Alpha wave, EEG
\end{abstract}

(This article was submitted Apr. 9, 2018, and was accepted Jun. 29, 2018)

\section{INTRODUCTION}

Acquired physical disabilities have been associated with an increased risk for subsequently developing post-traumatic stress disorder (PTSD) symptoms as well as cognitive problems ${ }^{1-3}$. Several lines of evidence reported that the dominant frequency ranges of brain wave activity as measured by electroencephalography (EEG) in people who suffer from PTSD differ from those in non-stressed people ${ }^{4-6)}$. EEG is a well-known technique for measuring brain activity by dividing it into four common brain wave ranges, these being delta $(0.5-4 \mathrm{~Hz})$, theta $(4-8 \mathrm{~Hz})$, alpha $(8-13 \mathrm{~Hz})$, and beta waves $(>13 \mathrm{~Hz})$. The alpha wave range is dominant during the waking state with closed eyes, and indicates conscious attention and relaxation. The beta wave range is dominant during the normal state of wakefulness with open eyes, and also correlates with tension, stress and anxiety ${ }^{7}$. Previous studies demonstrated that people diagnosed with PTSD present with abnormalities in brain activity in the form of decreased alpha and increased beta range activity ${ }^{5,6,8)}$. Moreover, recording the P300 event-related potential (ERP), another EEG-derived measurement ${ }^{9)}$, revealed a significant reduction in amplitude of the auditory P300 in patients with depression, indicating stress-related impairment of attention and concentration ${ }^{10)}$.

*Corresponding author. Amornpan Ajjimaporn (E-mail: g4036011@gmail.com)

(C2018 The Society of Physical Therapy Science. Published by IPEC Inc.

(c) (1) $\odot$ This is an open-access article distributed under the terms of the Creative Commons Attribution Non-Commercial No Derivatives CC. ${ }_{\text {BY }}$ ND (by-nc-nd) License. (CC-BY-NC-ND 4.0: https://creativecommons.org/licenses/by-nc-nd/4.0/) 
Hatha yoga is one aspect of the traditional path of yoga and the most popular form of yoga practiced in Western countries ${ }^{11)}$. It uses physical poses (asanas), breathing techniques (pranayamas), and meditation, which in combination are believed to improve both physical and mental outcomes to achieve better health through down-regulation of the hypothalamic-pituitaryadrenal (HPA) axis and the sympathetic nervous system (SNS) ${ }^{12)}$. Recently, Rachiwong et al. demonstrated an improvement in physical fitness parameters after 8 weeks of a modified hatha yoga training intervention in the injured workers. These improvements support the notion that the practice of hatha yoga may adjunct to routine physical therapy treatment in rehabilitation programs ${ }^{13}$. In addition, Uebelacker et al. examined the effects of a 10-week hatha yoga intervention on cognitive function in 50 persistently depressed individuals. The findings of this study suggest that the practice of hatha yoga may improve attention to the present moment and acceptance of one's self and one's experience in this population ${ }^{14)}$.

Several studies have examined the effects of yoga on brain activity as measured by EEG. Khare and Nigam investigated the effect of 12 weeks of yoga training on brain wave activity in 30 healthy participants and reported that yoga training increased the alpha index in the yoga group compared to the control group ${ }^{15)}$. In support of these findings, other similar studies have also shown increases in alpha, delta, and theta activities and a decrease in beta activity following yoga practice ${ }^{16,17)}$. However, these studies have all focused on healthy adults; we believe none has examined the effects of yoga on brain wave activity and cognitive ERP in physical disabilities resulting from injuries. Elucidating brain activity following hatha yoga training could provide insights into brain adaptation in the people following physical impairment and support the psychophysiological effects of yoga as an adjunct to routine rehabilitation. Therefore, the aim of this study was to examine the effects of an 8-week modified hatha yoga training program on brainwave activity and ERP using auditory reaction time (auditory RT), response accuracy (RA) for target stimuli and commission error which indicated the wrong response to standard stimuli, and the P300 ERP in patients with physical disability-related stress.

\section{PARTICIPANTS AND METHODS}

Eighteen workers with physical disabilities (ten males and eight females) aged from 18 to 55 years participated in this study. The participants were divided into two groups, an untrained control group $(\mathrm{CG} ; \mathrm{n}=9)$ and a group to be trained in modified hatha yoga (TG; $n=9)$, using purposive sampling strategies for both groups. Participants were recruited from the inpatient program at the Industrial Rehabilitation Center (IRC), Ministry of Labor, Thailand. Inclusion criteria included: 1) an onset of injury no longer than 6 months prior, 2) normal vision and hearing, 3) either a diagnosis of paraplegia or the acquired absence of a limb (Corset 3.1; G82 or Z89 respectively) as classified by the International Classification of Diseases ${ }^{18)}$, and 4) a high mean stress score (more than 25) as assessed by the Suanprung Stress Test-20 (SPST-20) ${ }^{19}$ ). Exclusion criteria included left-handed, illiterate, had a poor attention span (self-reported), taking medications from the group of antidepressants and/or antihistamines. Both groups were matched for gender (male:female=5:4) and type of injuries (The lumbar (L) spinal cord injury at the L4, and L5 vertebrae; Paraplegia, $\mathrm{n}=2$, Acquired absence of finger(s) [including thumb], unilateral, $\mathrm{n}=2$, Acquired absence of hand and wrist, $\mathrm{n}=2$, Acquired absence of upper limb above wrist, $\mathrm{n}=2$, and Acquired absence of foot and ankle, $n=1)$. The study was approved by the Ethics Committee on Human Experimentation of Mahidol University (MU-IRB 2014/016.2301). After providing informed consent, the demographic data of the participants were recorded. An EEG and auditory P300 analysis was conducted prior to and again after the 8-weeks of modified hatha yoga training.

The TG practiced a specific set of modified hatha yoga postures for 60 min three times per week over 8 weeks. The training was always performed at the same time of the day (8:00 am to 9:00 am) to reduce circadian variation. Participants did not have any experience with yoga or meditation. The first week of training was an adaptation week. The hatha yoga training program was modified for the level and specific disabilities of the participants by two certified yoga instructors and approved by the physical therapists (Fig. 1). The details of the modified hatha yoga training program have been described in a previous study ${ }^{13}$. The routine was practiced as a group following a DVD recording and conducted by instructors in a silent room. Both groups were instructed to continue with their ordinary rehabilitation programs at the IRC throughout the course of this study.

Participants were asked to avoid any substances that are known to influence cognitive performance, such as CNS-affecting drugs, caffeine, and alcoholic beverages, before the day of the recording. In addition, participants were advised to wash their hair, avoiding the use of hair spray or oil. The EEG and ERP measurements were performed in a dimly lit room with air conditioning and participants were seated in an adjustable comfortable chair in front of a computer screen.

The scalp skin was prepared and cleaned by 30\% alcohol and Nuprep (Compumedics, Neuroscan). For the EEG recording, $\mathrm{Ag} / \mathrm{AgCl}$ electrodes were attached to the Quik-Cap (Compumedics, Neuroscan). Electrodes were arranged on the EEG cap according to the international 10-20 placement system ${ }^{20)}$. The vertex of each participant's head was localized at the intersection of antero-posterior and left-to-right line and marked for the $\mathrm{Cz}$ electrode site on the Quik-Cap. Four electrooculogram (EOG) electrodes placed at both orbits were used for eye movement detection. All electrodes were referenced to the average value of both reference electrodes over the mastoid regions $(\mathrm{A} 1+\mathrm{A} 2 / 2)$. EEG gel was inserted into all electrode sites to keep the impedance below $5 \mathrm{k} \Omega$. Brain activities were initially recorded with eyes closed for 5 minutes using the Acquire Neuroscan version 4.3 recording system from Neurosoft, Inc. An online filter was set to band pass with a low pass frequency of $60 \mathrm{~Hz}$ and a high pass frequency equal to the DC. The analog-to-digital rate was set to $500 \mathrm{~Hz}$, the gain was set at 19, and the notch filter to $50 \mathrm{~Hz}$. The absolute power $(\mu \mathrm{V} 2)$ of the respective frequency bands derived by fast Fourier transforms (FFT) was defined for the delta $(0.5-4 \mathrm{~Hz})$, theta $(4.5-8 \mathrm{~Hz})$, alpha $(8.5-13 \mathrm{~Hz})$, and beta $(13.5-30 \mathrm{~Hz})$ wave ranges $\left.{ }^{7}\right)$. In the EEG analysis, the 


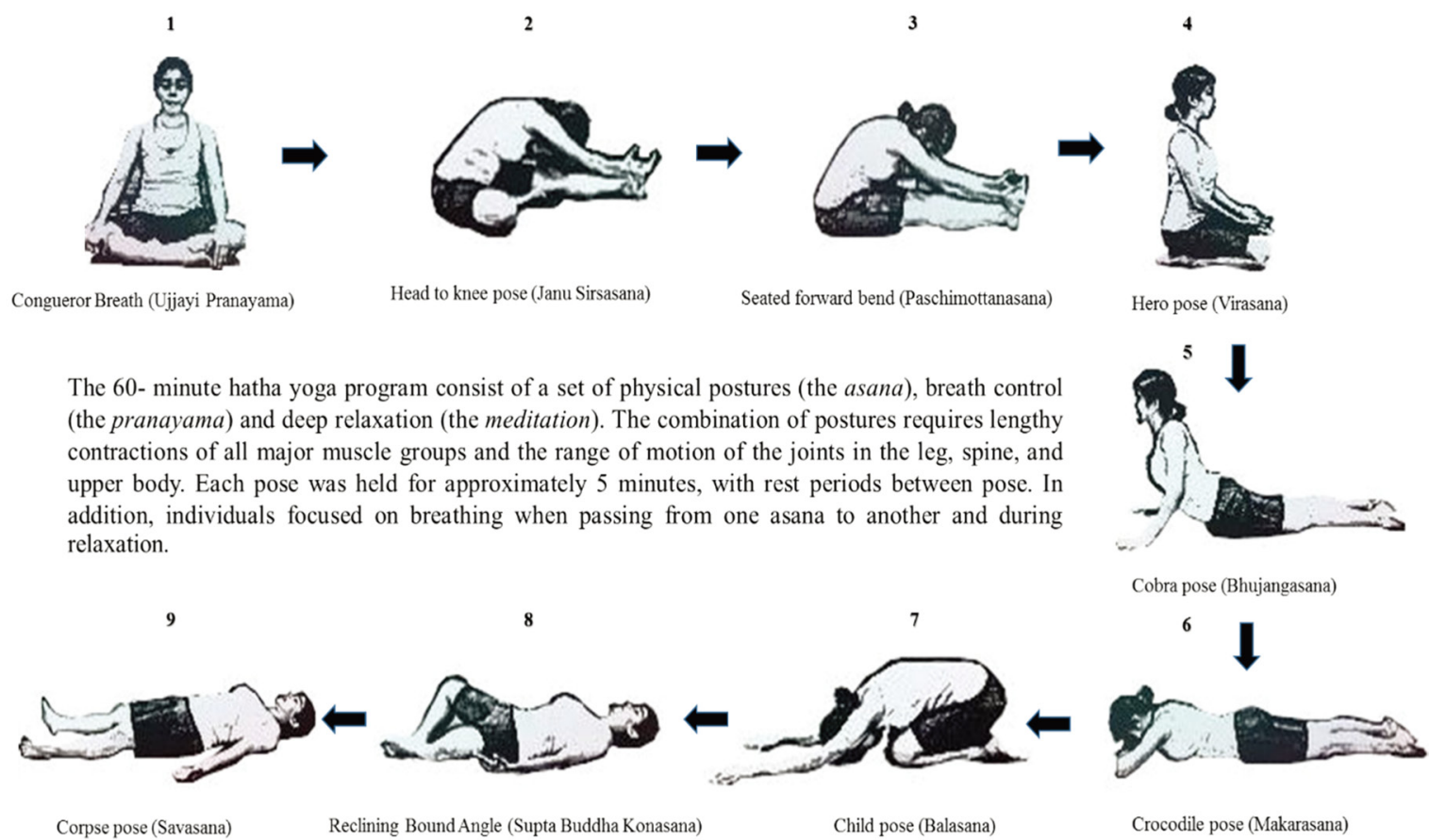

Fig. 1. Sequence of modified hatha yoga postures.

absolute power was calculated for each frequency band (delta, theta, alpha, and beta) during the eyes-closed resting conditions.

After the baseline spontaneous EEG recording, the ERP were recorded using an auditory oddball paradigm (auditory OP). The oddball paradigm is the standard task for the measurement of attention. During the task, two types of sound, either a low-pitch standard sound $(1,000 \mathrm{~Hz})$ or a high-pitch target sound $(2,000 \mathrm{~Hz})$, are presented to the participant in a random sequence. The percentage of standard stimuli was set to $85 \%$, with the target stimuli making up the remaining $15 \%$. The auditory stimuli were delivered through close fitting earphones. Participants were instructed to press a button when the target sound was presented. The reaction time (RT), percent accuracy for target stimuli, and commission error for standard stimuli were collected as indicators of behavioral performance.

For the ERP recording, the peak amplitudes and latencies of the P300 wave were measured over the midline central $(\mathrm{Cz})$, centroparietal $(\mathrm{CPz})$, and midline parietal $(\mathrm{Pz})$ electrode sites. The peak amplitude $(\mu \mathrm{V})$ was defined as the voltage difference between the baseline and the largest positive-going peak of the ERP waveform within 260-500 ms after stimulus presentation $^{21)}$. The peak latency (ms) was defined as the time from stimulus onset to the point of the maximum positive amplitude of the P300 wave. The duration of the ERP session was 12 minutes.

Statistical analysis was performed using the Statistical Package for the Social Sciences (SPSS) version 18.0. Data on participant characteristics were reported as a mean \pm SD. EEG activity data were reported as the mean absolute power of each brain wave frequency range. ERP data were reported as a mean \pm SEM. Normality was examined using the Shapiro-Wilk's test. Since the data were normally distributed, EEG and ERP variables were analyzed with repeated measures analyses of variance (ANOVA) with one between-groups factor (with two levels, i.e., CG and TG) and one within-group factor (with two levels, i.e., pre- and post-assessment). Significance was accepted at the $\mathrm{p}<0.05$ level.

\section{RESULTS}

There were no differences in the descriptive characteristics (age, weight, and height) of participants between groups (the respective values were $36 \pm 13$ years, $61 \pm 10 \mathrm{~kg}, 1.64 \pm 0.12 \mathrm{~m}$ for the $C G$ and $44 \pm 11$ years, $68 \pm 10 \mathrm{~kg}, 1.63 \pm 0.66 \mathrm{~m} \mathrm{for} \mathrm{the} \mathrm{TG).}$

The comparison of brain waves during the resting state between the CG and TG is shown in Table 1. The mean absolute powers of brain waves were calculated for each frequency band (delta, theta, alpha, and beta) in the eyes-closed condition. The TG demonstrated a significant increase in the mean power of alpha waves over the frontal $(\mathrm{Fz})$, central $(\mathrm{Cz})$, and parietal $(\mathrm{Pz})$ electrodes in the midline area and the mean power of delta waves over the centroparietal $(\mathrm{CPz})$ electrodes; the mean absolute powers of the theta and beta ranges had not significantly changed after the 8 weeks of modified hatha yoga training. Moreover, after training, the brain's topographical map revealed a wider spreading of alpha waves across the central region during the eyesclosed condition in the TG (Fig. 2). As expected, the absolute power of delta, theta, alpha, and beta waves in all regions evaluated remained unchanged after 8 weeks in the CG. There was no difference in mean power of brain waves between the CG and TG. 
Table 1. The mean power of brain waves during resting (eyeclosed recording) in untrained injured worker (CG) and modified hatha yoga (TG) group at pre- and posthatha yoga training

\begin{tabular}{|c|c|c|c|c|}
\hline \multirow{3}{*}{ Central area } & \multicolumn{4}{|c|}{ Mean power of brain waves $\left(\mu \mathrm{V}^{2}\right)$} \\
\hline & \multicolumn{2}{|c|}{$\mathrm{CG}$} & \multicolumn{2}{|c|}{ TG } \\
\hline & Pre- & Post- & Pre- & Post- \\
\hline \multicolumn{5}{|l|}{$\mathrm{Fz}$} \\
\hline Delta & 7.19 & 5.46 & 4.39 & 7.22 \\
\hline Theta & 4.71 & 3.35 & 3.46 & 5.41 \\
\hline Alpha & 6.50 & 3.33 & 3.55 & $6.30^{*}$ \\
\hline Beta & 0.48 & 0.45 & 0.56 & 0.47 \\
\hline \multicolumn{5}{|l|}{$\mathrm{FCz}$} \\
\hline Delta & 7.11 & 5.74 & 4.29 & 7.47 \\
\hline Theta & 4.56 & 3.35 & 3.49 & 5.32 \\
\hline Alpha & 6.77 & 3.45 & 5.17 & 5.79 \\
\hline Beta & 0.5 & 0.45 & 0.62 & 0.49 \\
\hline \multicolumn{5}{|l|}{$\mathrm{Cz}$} \\
\hline Delta & 7.02 & 5.08 & 3.79 & 6.48 \\
\hline Theta & 4.46 & 2.90 & 3.00 & 4.57 \\
\hline Alpha & 6.35 & 3.25 & 3.52 & $5.51^{*}$ \\
\hline Beta & 0.47 & 0.44 & 0.58 & 0.47 \\
\hline \multicolumn{5}{|l|}{$\mathrm{CPz}$} \\
\hline Delta & 5.11 & 4.37 & 3.09 & $4.97^{*}$ \\
\hline Theta & 3.31 & 2.56 & 2.58 & 3.44 \\
\hline Alpha & 5.48 & 3.16 & 5.44 & 5.92 \\
\hline Beta & 0.42 & 0.41 & 0.46 & 0.42 \\
\hline \multicolumn{5}{|l|}{$\mathrm{Pz}$} \\
\hline Delta & 3.79 & 3.67 & 2.73 & 3.99 \\
\hline Theta & 2.68 & 2.36 & 2.34 & 2.90 \\
\hline Alpha & 4.31 & 3.34 & 2.82 & $4.08^{*}$ \\
\hline Beta & 0.37 & 0.41 & 0.43 & 0.38 \\
\hline
\end{tabular}

*Significantly different between pre- and post-assessments, $\mathrm{p}<0.05$.
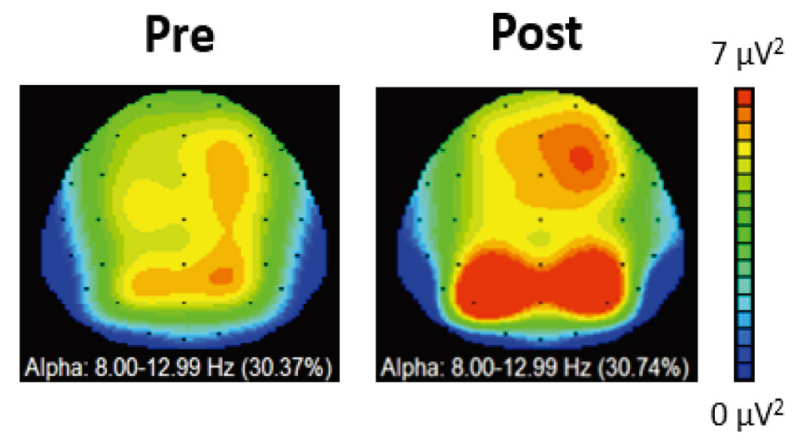

Fig. 2. The averaged brain topographical map for the distribution of alpha activities of the modified hatha yoga trained group (TG; $n=9$ ) at pre- and post- hatha yoga training. The red color indicates the higher brain wave power.

The RT in auditory OP for the TG showed a significant decrease after the hatha yoga training program. However, there were no statistically significant differences in percent accuracy and commission error between the CG and TG (Table 2). A comparison of the respective auditory P300 wave generated in auditory OP is shown in Table 3. P300 latency was significantly decreased at the $\mathrm{Cz}$ electrode in the TG after the modified hatha yoga training. There was no difference in the P300 components between the CG and TG.

\section{DISCUSSION}

To the best of the authors' knowledge, this was the first study observing brain wave activity and cognitive ERP in the patients with physical disability-related stress to elucidate the therapeutic effects for stress reduction of hatha yoga training. The main finding of this study was that the injured patients with stress who practiced modified hatha yoga for $60 \mathrm{~min}$ three times per week over 8 weeks experienced increased alpha and delta activity and improvements in ERP components, namely a shortening of the auditory RT and P300 peak latency in auditory OP.

In the TG, the mean alpha power over frontal, central, and parietal regions as well as the delta power over centroparietal region of electrode sites increased after the modified hatha yoga training compared to the pre-training baseline. These results demonstrate that modified hatha yoga training can increase alpha and delta dominance in the anterior two thirds of the patient's brain, which may reflect an enhancement of neuronal co-activation and suggest improvements in functional integration between these areas, as improved cognitive flexibility and emotional stability ${ }^{22,23)}$. Ganpat et al. have shown that a 21-day Integrated Yoga Module practice in 30 university students significantly increased alpha and delta EEG coherence, which indicates the efficacy of yoga for improving mental performance ${ }^{23}$. A significant increase in delta activity may be associated with a heightened efficiency of brain functioning ${ }^{24)}$ and may result in an improvement of mental performance ${ }^{23)}$. Furthermore, during relaxed wakefulness, the human brain exhibits pronounced rhythmic electrical activity with highest power in the alpha frequency band ${ }^{25}$. The observed increase in alpha-band rhythms may be associated with a decrease in cortical activity with a concomitant increase in signaling from the thalamus, which may be associated with stress-reduction and deep relaxation ${ }^{26,27)}$. This outcome is in line with those of previous yoga studies which showed changes in alpha activity measured by EEG following yoga training in healthy individuals $\left.{ }^{15}, 22,23,26\right)$. Khare and Nigam reported that the alpha index was higher in participants after practicing meditation ${ }^{15)}$. Kumar and Joshi have shown that the mean power in the alpha range was higher in 80 healthy young adults after they had been performing a daily 30-min yoga nidra (yogic sleep) session for 40 days, indicating an increase in mental relaxation ${ }^{26)}$. Therefore, these findings suggest that physical postures (asanas), controlled respiration (pranayama), and deep relaxation (meditation) as part of a hatha yoga program exert psychophysiological effects on brain activity associated with improving cognitive performance, reducing stress, and promoting relaxation in patients with physical disability-related stress. 
Table 2. Mean \pm SEM of reaction time, percent accuracy and commission error in auditory oddball paradigm in untrained injured worker (CG) and modified hatha yoga (TG) group at pre- and post-hatha yoga training

\begin{tabular}{lccccc}
\hline \multirow{2}{*}{ Behavioral data } & \multicolumn{2}{c}{ CG } & \multicolumn{2}{c}{ TG } \\
\cline { 2 - 3 } \cline { 5 - 6 } & Pre- & Post- & & Pre- & Post- \\
\cline { 2 - 5 } & $404 \pm 17$ & $415 \pm 19$ & & $383 \pm 26$ & $356 \pm 23^{*}$ \\
Reaction time (ms) & $79 \pm 5$ & $73 \pm 9$ & & $86 \pm 9$ & $90 \pm 6$ \\
Accuracy (\%) & $0.5 \pm 0.2$ & $0.3 \pm 0.1$ & & $0.7 \pm 0.2$ & $0.7 \pm 0.2$ \\
Commission error (\%) & &
\end{tabular}

*Significantly different between pre- and post-assessments, $\mathrm{p}<0.05$.

Table 3. Mean \pm SEM of peak amplitude $(\mu \mathrm{V})$ and peak latencies $(\mathrm{ms})$ of the P300 component in auditory oddball paradigm in untrained injured worker $(\mathrm{CG})$ and modified hatha yoga (TG) group at pre- and post-hatha yoga training

\begin{tabular}{|c|c|c|c|c|}
\hline \multirow{3}{*}{ Electrode position of $\mathrm{P} 300$} & \multicolumn{4}{|c|}{ Auditory oddball paradigm } \\
\hline & \multicolumn{2}{|c|}{$\mathrm{CG}$} & \multicolumn{2}{|c|}{$\mathrm{TG}$} \\
\hline & Pre- & Post- & Pre- & Post- \\
\hline \multicolumn{5}{|l|}{$\mathrm{Cz}$} \\
\hline Amplitude $(\mu \mathrm{V})$ & $5.5 \pm 1.5$ & $9.2 \pm 2.7$ & $9.2 \pm 2.3$ & $9.2 \pm 3.3$ \\
\hline Latency (ms) & $395 \pm 11$ & $395 \pm 10$ & $400 \pm 16$ & $380 \pm 17^{*}$ \\
\hline \multicolumn{5}{|l|}{$\mathrm{CPz}$} \\
\hline Amplitude $(\mu \mathrm{V})$ & $6.6 \pm 1.5$ & $9.4 \pm 2.4$ & $8.4 \pm 2.1$ & $9.4 \pm 2.8$ \\
\hline Latency (ms) & $403 \pm 2$ & $410 \pm 6$ & $400 \pm 13$ & $387 \pm 18$ \\
\hline \multicolumn{5}{|l|}{$\mathrm{Pz}$} \\
\hline Amplitude $(\mu \mathrm{V})$ & $6.7 \pm 1.7$ & $8.5 \pm 2.1$ & $7.4 \pm 1.5$ & $9.2 \pm 1.9$ \\
\hline Latency (ms) & $408 \pm 7$ & $413 \pm 7$ & $400 \pm 11$ & $392 \pm 13$ \\
\hline
\end{tabular}

*Significantly different between pre- and post-assessments, $\mathrm{p}<0.05$.

The results from behavioral data and ERP recordings in the auditory OP showed that after 8 weeks, the TG had a significantly shorter auditory RT than before the yoga practice. This finding is consistent with those of Madanmohan et al. who reported that yoga training decreased auditory RT in post-menopausal patients with diabetes ${ }^{27}$. In addition, breathing techniques or pranayama as a part of hatha yoga may improve this cognitive task performance by 1) enhancing arousal and facilitating the rate of information processing, 2) increasing the capacity for concentration, and/or 3) inhibiting extraneous stimuli ${ }^{28)}$.

The data in this study demonstrate a significant decrease in P300 peak latency over the Cz electrode site in the TG after the yoga training. Shorter P300 latencies are associated with superior cognitive performance in tasks involving attention, immediate memory, and decision making, and might reflect response processing ${ }^{29}$. The data observed in this study are consistent with the ERP waveform changes found in patients with type 2 diabetes in a study by Kiyzom et al. who reported a decrease in the peak latency of $\mathrm{P} 300$ wave over the $\mathrm{Fz}, \mathrm{Cz}$ and $\mathrm{Pz}$ sites after pranayama and asana practice ${ }^{30)}$. Moreover, previous studies have also shown the P300 peak latency to be decreased after pranayama exercise ${ }^{31,32)}$. Therefore, a reduced P300 latency in the AOP could indicate faster neural transmission on the attention pathway. Taken together, our findings indicate that 8 weeks of modified hatha yoga practice could improve information processing and change attentional allocation in the injured patients.

The results should be interpreted in the context of limitation. One major limitation of this study is that it was carried out with a small patient population ( $\mathrm{CG}, \mathrm{n}=9$ and $\mathrm{TG}, \mathrm{n}=9$ ). Furthermore, the different types of injuries (Paraplegia, $\mathrm{n}=4$, Acquired absence of finger(s), $n=4$, Acquired absence of hand and wrist, $n=4$, Acquired absence of upper limb above wrist, $\mathrm{n}=4$, and Acquired absence of foot and ankle, $n=2$ ) could cause different yoga training responses and might affect the results of the study. Further evaluations should be carried out with larger sample sizes of injured patients with the same types of disabilities to sharpen the results of interest.

The present study provided psychophysiological evidence that an 8-week modified hatha yoga program could promote relaxation and stress reduction as revealed by an increase in alpha and delta activities. Moreover, the speed of information processing and attention performance were shown to improve following yoga training as evidenced by a faster RT and a shorter P300 peak latency. Thus, we concluded that modified hatha yoga training can be a safe and beneficial adjunct to routine rehabilitation in the patients with physical disabilities and stress symptoms. 


\section{ACKNOWLEDGEMENT}

The authors would like to thank Prof. James J Laskin, School of Physical Therapy \& Rehabilitation Sciences, The University of Montana, USA, for his editorial assistance on this manuscript.

\section{Funding}

This research did not receive any specific grant from funding agencies in the public, commercial, or not-for-profit sectors.

\section{Conflict of interest}

None.

\section{REFERENCES}

1) Asmundson GJ, Norton GR, Allerdings MD, et al.: Posttraumatic stress disorder and work-related injury. J Anxiety Disord, 1998, 12: 57-69. [Medline] [CrossRef]

2) Lynch SG, Parmenter BA, Denney DR: The association between cognitive impairment and physical disability in multiple sclerosis. Mult Scler, 2005, 11: 469-476. [Medline] [CrossRef]

3) Hughes RB, Taylor HB, Robinson-Whelen S, et al.: Stress and women with physical disabilities: identifying correlates. Womens Health Issues, 2005, 15: 14-20. [Medline] [CrossRef]

4) Hoffmann E: Brain training against stress. Theory, methods and results from an outcome study. Clinical EEG Journal, $2005,1-24$.

5) Veltmeyer MD, Clark CR, McFarlane AC, et al.: Integrative assessment of brain and cognitive function in post-traumatic stress disorder. J Integr Neurosci, 2005, 4: 145-159. [Medline] [CrossRef]

6) Begić D, Hotujac L, Jokić-Begić N: Electroencephalographic comparison of veterans with combat-related post-traumatic stress disorder and healthy subjects. Int J Psychophysiol, 2001, 40: 167-172. [Medline] [CrossRef]

7) Teplan M: Fundamentals of EEG measurement. Meas Sci Rev, 2002, 2: 1-11.

8) Jokić-Begić N, Begić D: Quantitative electroencephalogram (qEEG) in combat veterans with post-traumatic stress disorder (PTSD). Nord J Psychiatry, 2003, 57: 351-355. [Medline] [CrossRef]

9) Polich J: Updating P300: an integrative theory of P3a and P3b. Clin Neurophysiol, 2007, 118: 2128-2148. [Medline] [CrossRef]

10) Bruder GE, Kroppmann CJ, Kayser J, et al.: Reduced brain responses to novel sounds in depression: P3 findings in a novelty oddball task. Psychiatry Res, 2009 , 170: 218-223. [Medline] [CrossRef]

11) Riley D: Hatha yoga and the treatment of illness. Altern Ther Health Med, 2004, 10: 20-21. [Medline]

12) Ross A, Thomas S: The health benefits of yoga and exercise: a review of comparison studies. J Altern Complement Med, 2010, 16: 3-12. [Medline] [CrossRef]

13) Rachiwong S, Panasiriwong P, Saosomphop J, et al.: Effects of modified hatha yoga in industrial rehabilitation on physical fitness and stress of injured workers. J Occup Rehabil, 2015, 25: 669-674. [Medline] [CrossRef]

14) Uebelacker LA, Kraines M, Broughton MK, et al.: Perceptions of hatha yoga amongst persistently depressed individuals enrolled in a trial of yoga for depression. Complement Ther Med, 2017, 34: 149-155. [Medline] [CrossRef]

15) Khare KC, Nigam SK: A study of electroencephalogram in meditators. Indian J Physiol Pharmacol, 2000, 44: 173-178. [Medline]

16) Bharadwaj I, Anuja KA: Effect of yogic intervention on blood pressure and alpha-EEG level of working women. Indian J Tradit Knowl, 2013, 12: 542-546.

17) Ganpat TS, Nagendra HR, Muralidhar K: Effects of yoga on brain wave coherence in executives. Indian J Physiol Pharmacol, 2011, 55: 304-308. [Medline]

18) World Health Organization International Classification of Diseases (ICD): http://www.who.int/classifications/icd/en/ (Accessed Apr. 10, 2016)

19) Mahatnirunkul S, Pumpisanchai W, Tapanya P: The construction of Suan Prung stress test for Thai population. Bull Suan Prung, 1997, 13: 1-11 [article in Thai language].

20) Klem GH, Lüders HO, Jasper HH, et al. The International Federation of Clinical Neurophysiology: The ten-twenty electrode system of the International Federation. Electroencephalogr Clin Neurophysiol Suppl, 1999, 52: 3-6. [Medline]

21) Polich J, Heine MR: P300 topography and modality effects from a single-stimulus paradigm. Psychophysiology, 1996, 33: 747-752. [Medline] [CrossRef]

22) Cahn BR, Polich J: Meditation states and traits: EEG, ERP, and neuroimaging studies. Psychol Bull, 2006, 132: 180-211. [Medline] [CrossRef]

23) Ganpat TS, Nagendra HR, Selvi V: Efficacy of yoga for mental performance in university students. Indian J Psychiatry, 2013, 55: 349-352. [Medline] [CrossRef]

24) Mason LI, Alexander CN, Travis FT, et al.: Electrophysiological correlates of higher states of consciousness during sleep in long-term practitioners of the Transcendental Meditation program. Sleep, 1997, 20: 102-110. [Medline] [CrossRef]

25) Hughes SW, Crunelli V: Thalamic mechanisms of EEG alpha rhythms and their pathological implications. Neuroscientist, 2005, 11: 357-372. [Medline] [CrossRef]

26) Kumar K, Joshi A: Study on the effect of yoga Nidra \& Pranakarshan pranayama on alpha EEG \& GSR. Indian J Tradit Knowl, 2009, 8: 453-454.

27) Madanmohan, Thombre DP, Balakumar B, et al.: Effect of yoga training on reaction time, respiratory endurance and muscle strength. Indian J Physiol Pharmacol, 1992, 36: 229-233. [Medline]

28) Bhavanani AB, Madanmohan, Udupa K: Acute effect of Mukh bhastrika (a yogic bellows type breathing) on reaction time. Indian J Physiol Pharmacol, 2003, 47: 297-300. [Medline]

29) Telles S, Singh N, Puthige R: Changes in P300 following alternate nostril yoga breathing and breath awareness. Biopsychosoc Med, 2013, 7: 11. [Medline] [CrossRef]

30) Kyizom T, Singh S, Singh KP, et al.: Effect of pranayama \& yoga-asana on cognitive brain functions in type 2 diabetes-P3 event related evoked potential (ERP). Indian J Med Res, 2010, 131: 636-640. [Medline]

31) Telles S, Joshi M, Somvanshi P: Yoga breathing through a particular nostril is associated with contralateral event-related potential changes. Int J Yoga, 2012, 5: 102-107. [Medline] [CrossRef]

32) Telles S, Raghuraj P, Maharana S, et al.: Immediate effect of three yoga breathing techniques on performance on a letter-cancellation task. Percept Mot Skills, 2007, 104: 1289-1296. [Medline] [CrossRef] 